\title{
HYPERTENSION IN ACROMEGALY PATIENTS WITH OBSTRUCTIVE SLEEP APNEA
}

\author{
U. Tsoy, L. Korostovtseva, Y. Sviryaev, A.Semenov, D.Vaulina, S. Kravchenko, A. Konradi, E. Grineva
}

Federal Almazov North-West Medical Research Centre, St-Petersburg, Russian Federation

Objectives

\section{$\operatorname{Aim}$}

\section{Methods}

\section{Results}

Hypertension is an independent factor of cardiovascular morbidity in acromegaly patients[1]. Obstructive sleep disordered breathing (SDB) is the most common respiratory impairment in acromegaly and is considered one of the mechanisms underlying the development of hypertension in this disorder [2].

To study blood pressure parameters and prevalence of hypertension in naïve acromegaly patients depending on the presence of moderate-to-severe obstructive sleep apnea.

Patients characteristics: Forty-eight naïve acromegalic patients (11 men, 37 women, median age 53,5 (27-76) years were recruited into the study. Median GH was $12,3(2,2-166,6) \mathrm{ng} / \mathrm{ml}$, median IGF-1 534,7 (239,2-1561)mcg/l.

Methods:

- Full polysomnography (Embla N7000, MedCare Flaga, Iceland).

- Sleep-breathing disorders were diagnosed if apnea/hypopnea index (AHI) was $\geq 5$ events/hour, defined as mild if AHI 5$14,9 / \mathrm{h}$, moderate if $\mathrm{AHI} 15-29,9 / \mathrm{h}$, severe if $\mathrm{AHI} \geq 30$.

-Blood pressure (BP), estimated during the first clinic visit, was defined as office blood pressure.

-Twenty-four-hour blood pressure monitoring was performed by Watch BP device (Microlife, Switzerland)

$>$ SDB, namely obstructive sleep apnea, was found in 36 (75\%) patients

$>$ Thirteen patients (36\%) had mild, eleven (31\%) - moderate and twelve (33\%) showed severe OSA. The latter two groups (moderate-to-severe OSA, further referred as patients with OSA) were compared to patients without OSA (non-OSA) $>$ In patients with OSA office diastolic blood pressure was significantly higher than in patients without OSA (Tab. 1) $>$ According to 24-hour BPM mean 24-hour, daytime and nighttime blood pressure were significantly higher in patients with OSA as compare to non-OSA subjects (Fig.1)

$>$ The rate of office hypertension $\left(\chi^{2}=3,85 ; p<0,05\right)$, mean 24-hour $\left(\chi^{2}=4,8 ; p=0,03\right)$ and nighttime hypertension $\left(\chi^{2}=\right.$ $5,23 ; p<0,03)$ was significantly higher in OSA group, while the frequency of daytime hypertension was similar in both groups

Tab.1 Office blood pressure

\begin{tabular}{|l|l|l|l|}
\hline & $\begin{array}{l}\text { Patients } \\
\text { without } \\
\text { SA (n=12) }\end{array}$ & $\begin{array}{l}\text { Patients } \\
\text { with OSA (n=28) }\end{array}$ & Significance \\
\hline $\begin{array}{l}\text { Systolic } \\
\text { BP, mmHg }\end{array}$ & $\begin{array}{l}134 \\
(112-173)\end{array}$ & $\begin{array}{l}141 \\
(109-180)\end{array}$ & $\mathrm{p}=0,11$ \\
\hline $\begin{array}{l}\text { Diastolic } \\
\text { BP, } \mathrm{mmHg}\end{array}$ & $\begin{array}{l}80 \\
(70-89)\end{array}$ & $\begin{array}{l}92 \\
(74-100)\end{array}$ & $\mathrm{p}=0,029$ \\
\hline
\end{tabular}

Fig 1.Twenty-four-hour blood pressure monitoring

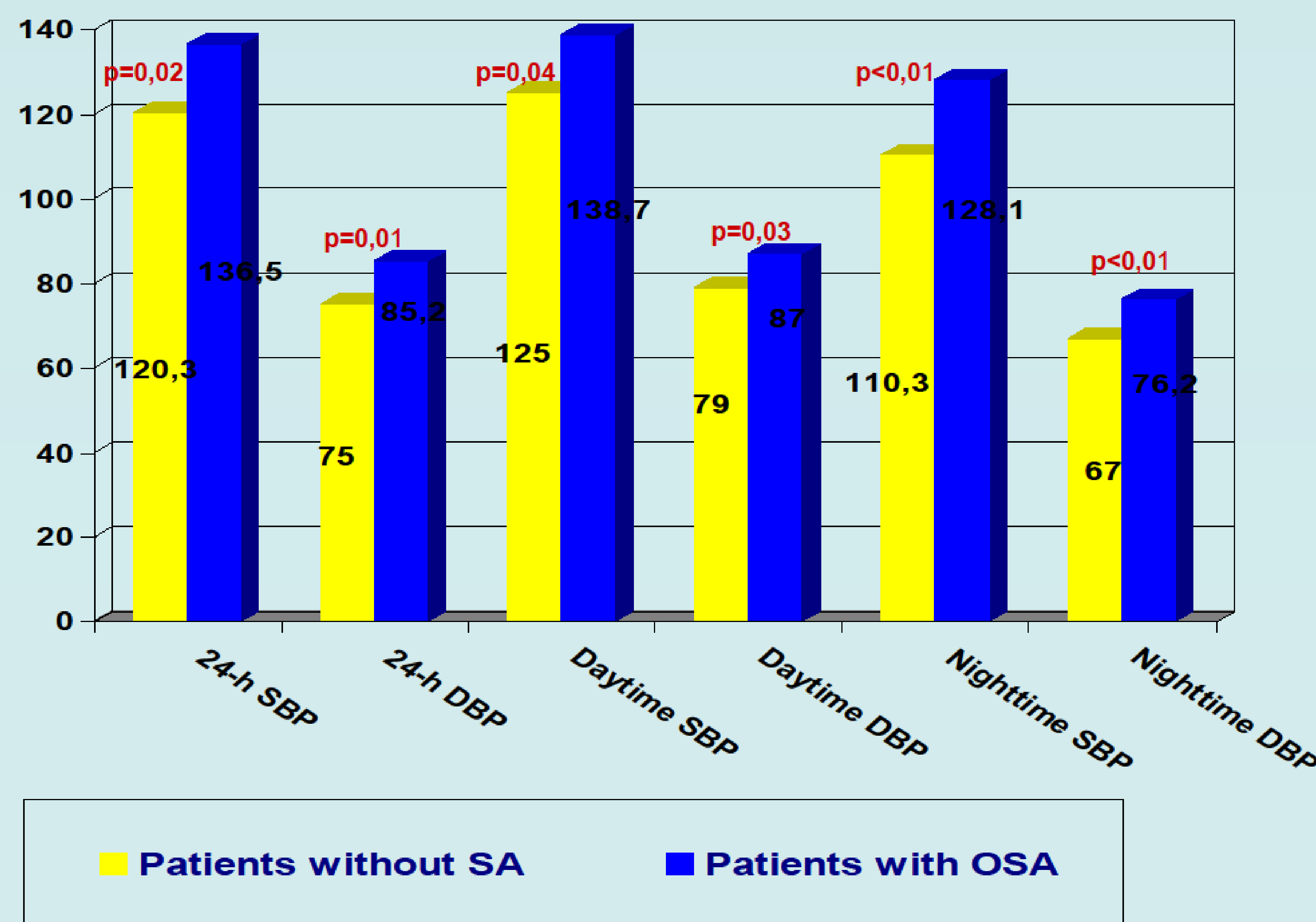

Conclusions

\section{References}

According to the office measurement and 24-hour BPM the blood pressure parameters and prevalence of hypertension were higher in patients with OSA. Our data support that patients with newly diagnosed acromegaly should be recommended to undergo polysomnography study in order to detect ones at higher risk of hypertension development.

1. Holdaway IM, Rajasoorya RC. Factors influencing mortality in acromegaly. J Clin Endocrinol Metab. 2004;89(2):667-74.

2. Mosca S, Paolillo S, Colao A et al. Cardiovascular involvement in patients affected by acromegaly: An appraisal. Int J Cardiol. 2013;167(5):1712-18.

\section{6--EP}

